\title{
Feasibility of Orion Crew Module Entry on Half of Available Propellant Due to Tank Isolation Fault
}

\author{
Marina M. Moen ${ }^{1}$ \\ NASA Langley Research Center, Hampton, VA, 23696
}

\begin{abstract}
The fuel tank isolation as a result of leak or rupture can leave an Orion Crew Module with only half of the loaded propellant for ISS return atmospheric entry. To assess the feasibility of returning under this condition, an analysis of various entry control options with deliberate degradation of control performance was performed. The study determined that a ballistic entry without a raise burn, a steeper flight path trajectory, relaxed atmospheric pitch/yaw rate damping, and degraded touchdown control could achieve 2- $\sigma$ requirements compliance with a 2- $\sigma$ fuel usage that is less than half of the liftoff propellant loading. The results of this analysis indicate that an entry with only half the nominal propellant load is feasible following a tank isolation fault.
\end{abstract}

\section{Nomenclature}

$\begin{array}{ll}\text { GN\&C } & =\text { guidance, navigation, and control } \\ \text { CEV } & =\text { crew exploration vehicle } \\ \text { CM } & =\text { crew module } \\ \text { EI } & =\text { entry interface } \\ \text { ISS } & =\text { International Space Station } \\ \text { LAS } & =\text { launch abort system } \\ \text { LMG } & =\text { loads managed guidance } \\ \text { RCS } & =\text { reaction control system } \\ \text { SA } & =\text { spacecraft adepter } \\ \text { SM } & =\text { service module } \\ I_{\text {sp }} & =\text { specific impulse, } \mathrm{s} \\ \text { R } & =\text { roll jet } \\ \text { P } & =\text { pitch jet } \\ \mathrm{Y} & =\text { yaw jet }\end{array}$

\section{Introduction}

$\mathrm{T}_{\mathrm{b}}$ he Orion Crew Exploration Vehicle (CEV) was part of the NASA Constellation program, which was aimed at replacing the Space Shuttle with a vehicle that could deliver crew to the International Space Station (ISS). The CEV was to be launched on top of the Crew Launch Vehicle (CLV), also known as Ares I. Although the Constellation program has been largely canceled, the CEV is still in development as the new Multi-Purpose Crew Vehicle. It is planned to be launched on an as yet unidentified launch vehicle. Figure 1 shows $\mathrm{CEV}$ in

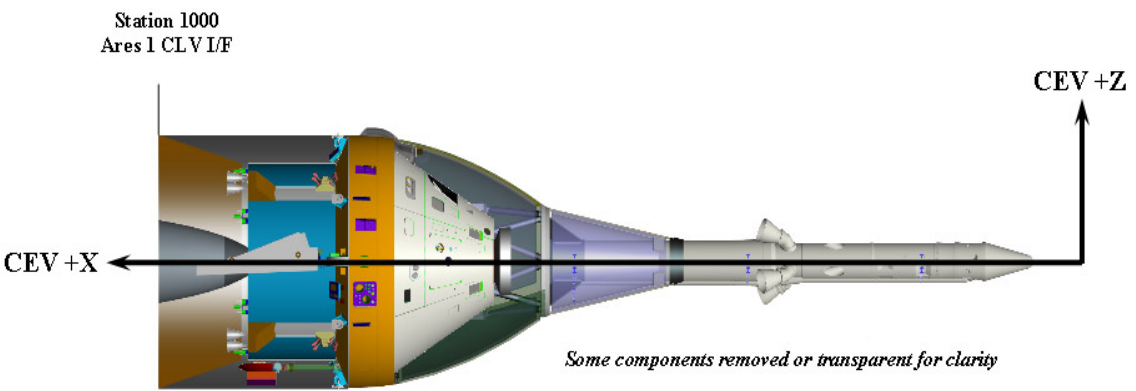

Figure 1. Orion CEV as part of Ares I upper stage.

\footnotetext{
${ }^{1}$ Aerospace Engineer, Vehicle Analysis Branch, MS 451, Member AIAA
}

1

American Institute of Aeronautics and Astronautics 
the original configuration as part of the Ares I upper stage.

As shown in Fig. 2, the Orion spacecraft is composed of three modules: a Crew Module (CM); an expendable Service Module (SM); and a Spacecraft Adapter (SA) to interface with the launch vehicle. Figure 2 also shows an expendable Launch Abort System (LAS) module.

While the vehicle is located at the ISS, the CM is mated to the SM; the LAS and SA components are jettisoned during ascent. During return (see Fig. 3), the SM reaction control system (RCS) delivers the SM-CM vehicle to the targeted deorbit attitude, then the SM is jettisoned, and a $\mathrm{CM}$ raise burn is performed. The $\mathrm{CM}$ raise burn is used to shallow the $\mathrm{CM}$ flight-path angle and to extend downrange distance to ensure that the $\mathrm{CM}$ remains outside the SM debris footprint. At the end of the CM raise burn, the CM reo-

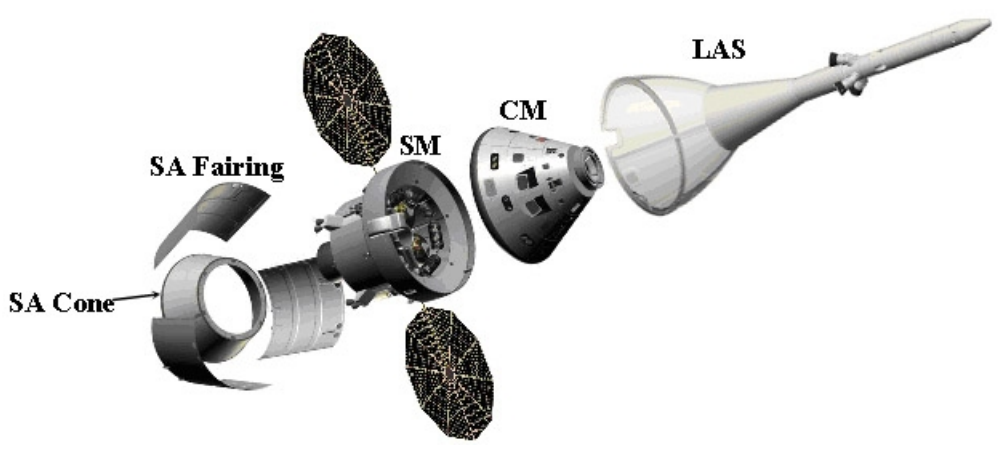

Figure 2. Orion CEV vehicle configuration.

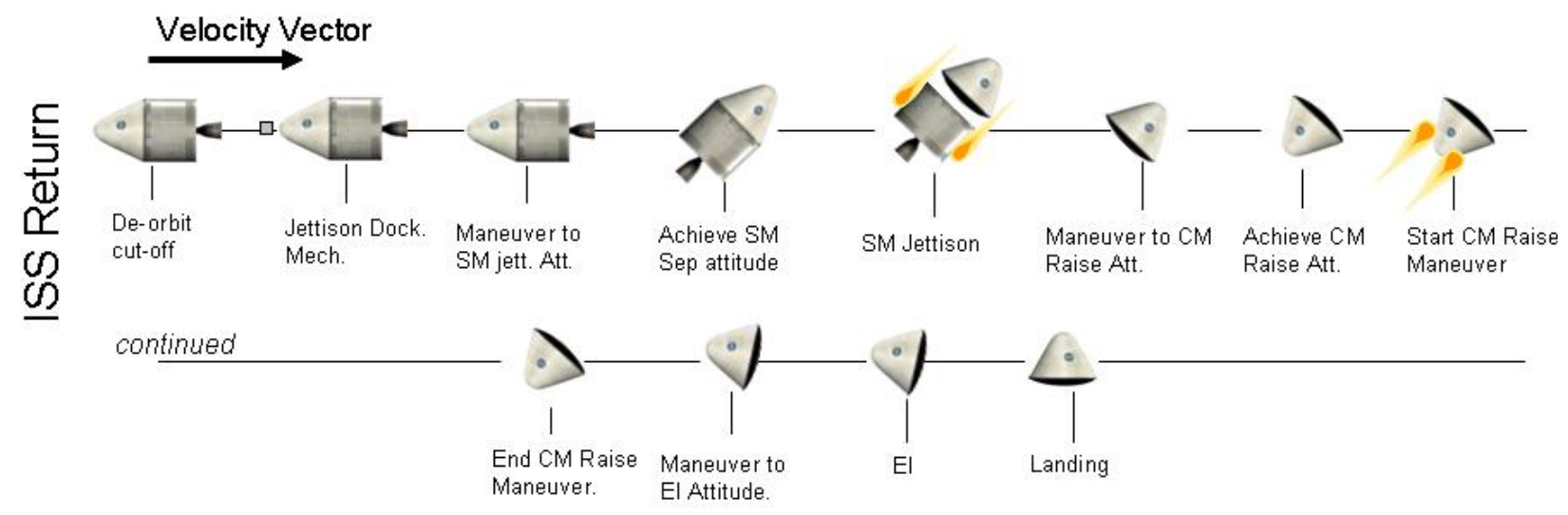

Figure 3. CM event sequence. ${ }^{1}$

rients to an entry interface (EI) attitude and enters the EI at 400,000 ft.

The CM RCS is characterized by two redundant jet strings, $\mathrm{A}$ and $\mathrm{B}$, which can be fired independently or concurrently (i.e., bi-level firing). A simplified propellant fuel schematic is shown in Fig. 4. The RCS strings are fed propellant from two separate sets of propellant tanks. In the case of tank leakage or rupture, the damaged tank is isolated by closing the line valves; this type of problem is considered a contingency fault. The result is that one-half of the propellant and the pressurant is unavailable to the propulsion system.

Various entry options with deliberate degradation of control performance were identified and analyzed to determine whether a return on one-

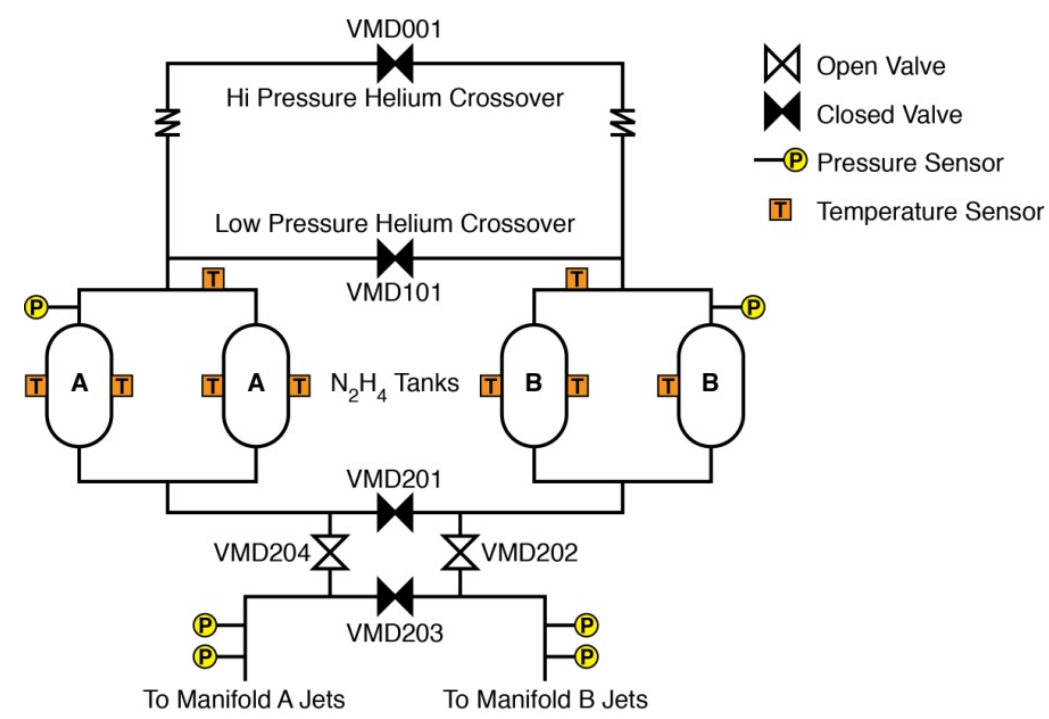

Figure 4. Simplified tank feed schematic.

American Institute of Aeronautics and Astronautics 
half of the available propellant would be feasible. The goal was the safe return of the crew to the surface with compliance for all guidance, navigation, and control (GN\&C) performance metrics. The study determined that ballistic entry with no CM raise burn, a steeper flight-path trajectory, relaxed atmospheric pitch and yaw rate damping, and degraded touchdown control could achieve compliance with GN\&C requirements with fuel usage that was equivalent to less than one-half of the liftoff propellant loading.

\section{Setup and Assumptions}

Because half of the pressurization system is lost, the tank isolation fault causes thrust and specific impulse $\left(I_{\mathrm{sp}}\right)$ reductions that are greater than those that occur during nominal operation. Hardware constraints limit the system to the simultaneous firing of no more than four simultaneous jets firing after a tank isolation fault. As a result, a single-string operation is the preferred operational mode for a tank isolation scenario. A single string consists of \pm -roll, \pm pitch, and \pm yaw jets. Strings A and B are identical in both thrust and $I_{\mathrm{sp}}$ magnitude and have similar locations on the CM body. Figure 5 shows the CM RCS positions for strings A and B (thrusters are identified with an 'R', 'P', or ' $\mathrm{Y}$ ' to indicate roll, pitch, or yaw, respectively). The logic to determine whether one or both strings are used is dependent on the flight phase, the necessary amount of thrust, and the flight mode.

Tank isolation event requires multiple faults: a tank rupture or leak or a low probability event, such as a micrometeoroid hit. Therefore, tank isolation is considered a contingency fault. For the purposes of this study, the assumption was made that performance requirements and CM propellant usage could be judged to a relaxed compliance level (i.e., 2- $\sigma$ rather than 3- $\sigma$ ). Therefore, feasibility was considered to be demonstrated if 2- $\sigma$ compliance was achieved.

The propellant budget was assumed to be $330 \mathrm{lbm}$ for an ISS return scenario starting at deorbit burn. Therefore, a return on one-half of the available propellant would require that the vehicle use no more than $165 \mathrm{lbm}$ of propellant during the flight. For consistency, the same version of the simulation software that was used to generate the original $330 \mathrm{lbm}$ propellant budget was also used for this study. Furthermore, the assumption was made that minimal fuel was lost from the "available" tanks as a result of cross-fed fuel lines prior to the detection and isolation of the damaged tanks. Calculation of any fuel loss from the available fuel tanks is neglected in the study.

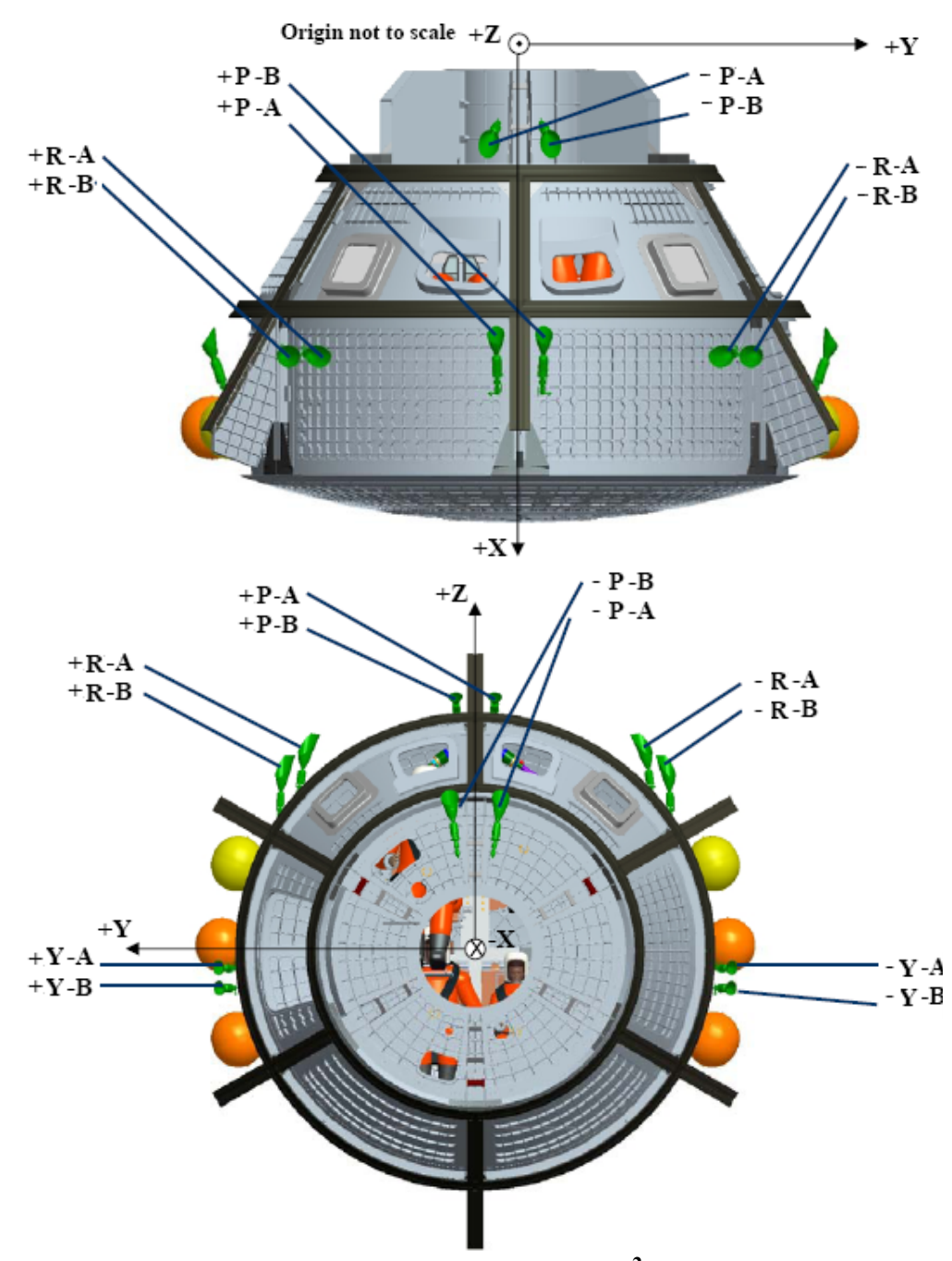

Figure 5. CM cutaway. ${ }^{2}$ 


\section{Results}

Three nominal contingency modes were examined as possible solutions: constant-bank, ballistic, and loadsmanaged. All three modes were simulated by using a 3000 run Monte Carlo from the deorbit point with a singlestring RCS and without a CM trajectory raise burn. Table 1 shows the mean and maximum propellant usage for the three modes segregated by entry flight phase. Table 2 shows end-to-end fuel usage statistics, including the minimum, mean, maximum, $1-\sigma$, and 2- $\sigma$ fuel usages. For a one-sided distribution problem, $2-\sigma$ is defined as the $57^{\text {th }}$ highest fuel usage, and $1-\sigma$ is defined as the $450^{\text {th }}$ highest fuel usage. For the touchdown heading requirement, the 2- $\sigma$ compliance has no more than 57 heading violations.

Table 1. Flight Phase CM Propellant Usage for Entry Abort Modes with no Raise Burn

\begin{tabular}{|c|c|c|c|c|c|c|c|}
\hline \multirow[t]{2}{*}{ (n) } & \multicolumn{2}{|c|}{ Deorbit to EI } & \multicolumn{2}{|c|}{$\begin{array}{c}\text { EI to } \\
\text { drogue } \\
\text { deployment }\end{array}$} & \multicolumn{2}{|c|}{$\begin{array}{c}\text { Drogue } \\
\text { deployment } \\
\text { to touchdown }\end{array}$} & \multirow{2}{*}{$\begin{array}{c}\text { Touchdown } \\
\text { heading } \\
\text { violations }\end{array}$} \\
\hline & $\begin{array}{l}\text { Mean } \\
\text { (lbm) }\end{array}$ & $\begin{array}{c}\text { Max } \\
\text { (lbm) }\end{array}$ & $\begin{array}{l}\text { Mean } \\
\text { (lbm) }\end{array}$ & $\begin{array}{l}\operatorname{Max} \\
\text { (lbm) }\end{array}$ & $\begin{array}{l}\text { Mean } \\
\text { (lbm) }\end{array}$ & $\begin{array}{c}\text { Max } \\
(\mathrm{lbm})\end{array}$ & \\
\hline Constant-bank & 4.45 & 6.43 & 35.89 & 63.10 & 61.75 & 165.23 & 2 \\
\hline Ballistic & 4.45 & 6.43 & 51.09 & 82.58 & 63.39 & 158.66 & 6 \\
\hline Loads-managed & 7.67 & 9.32 & 42.48 & 71.92 & 62.32 & 164.69 & 2 \\
\hline
\end{tabular}

The "Touchdown Heading Violation" column in Table 1 shows the number of cases from each abort mode that exceeded the earth relative velocity direction in the $+\mathrm{Z}$ axis during touchdown by the amount indicated by the green outline in Figs. 6 and 7. The required velocity direction accuracy is necessary to ensure crew survival during a water landing.

Table 2. End-to-End CM Propellant Usage for Entry Abort Modes with no Raise Burn

\begin{tabular}{|l|c|c|c|c|c|}
\cline { 2 - 6 } \multicolumn{1}{c|}{} & Min (lbm) & Mean (lbm) & Max (lbm) & 2- $\mathbf{( l b m )}$ & $\mathbf{1 - \sigma}(\mathbf{l b m})$ \\
\hline Constant-bank & 36.61 & 102.09 & 221.78 & 186.68 & 140.93 \\
Ballistic & 62.67 & 119.20 & 229.23 & 200.94 & 153.97 \\
Loads-managed & 53.94 & 112.48 & 231.54 & 198.50 & 151.35 \\
\hline
\end{tabular}

All three of the presented contingency modes used less than one-half of the available propellant with 1- $\sigma$ compliance but not with 2- $\sigma$ compliance. The constant-bank mode had the lowest propellant usage of the three modes. For all three cases, the "Drogue to touchdown" phase of the flight required almost one-half of the loaded propellant for the worst cases. Thus, the largest saving in propellant resulted from modifying the touchdown controller while still maintaining 2- $\sigma$ compliance with the heading at landing. Another option was to wait on orbit for calm winds and simply not use the touchdown control. In this case, the unmodified entry abort modes were sufficient to achieve a landing on one-half of the available propellant.

The entry abort modes can be modified in several other ways to reduce propellant consumption, including: relaxing the algorithm data settings (i.e., gains and deadbands), degrading the touchdown controller, and flying a steeper entry trajectory to reduce the atmospheric flight time. For the purposes of this study, it is assumed that the tank isolation is Fault Detection, Isolation, and Recovery driven and that the modification of data settings is permissible following a tank isolation event. In this study, changes to the algorithm were not permitted; only changes to the GN\&C data were allowed. Because touchdown control was the major source of fuel consumption in the baseline cases that are described in Tables 1 and 2, two options for degrading the touchdown controller were evaluated. One option eliminated the use of the RCS jets to damp the roll rates for CM while the drogue chutes are deployed, and the other relaxed the rate limit settings for the anti-twist algorithm that is used while the main chutes are deployed. The objective of these two touchdown control changes was to reduce fuel consumption while still achieving 2- $\sigma$ compliance for the touchdown heading envelope at landing. Tables 1 and 2 indicate that the ballistic abort mode consumes more fuel than the constant-bank or the loads-managed modes; thus, another consideration was to relax the control gains for the ballistic mode. In particular, with the use of the default settings in the ballistic mode, an

4

American Institute of Aeronautics and Astronautics 
excessive number of pitch and yaw jet firings were noted at subsonic speed. This can be seen in Table 3 by examining the total on-time statistics for each CM RCS jet for the ballistic mode (without a CM raise burn). To reduce the number of pitch and yaw firings, a reduction in the pitch and yaw rate damping control gains $\left(K_{\mathrm{q}}\right.$ and $\left.K_{\mathrm{r}}\right)$ was evaluated. For this study, the criterion for selecting new gains was the verification that the vehicle did not tumble prior to deployment of the drogue chutes.

Table 3. Jet On-Time Statistics Per CM RCS Jet for Ballistic Entry

\begin{tabular}{|c|c|c|c|c|c|c|c|c|}
\hline & \multicolumn{2}{|c|}{ Pre-EI } & \multicolumn{2}{|c|}{ EI to Mach 2} & \multicolumn{2}{|c|}{$\begin{array}{c}\text { Mach } 2 \text { to drogue } \\
\text { deployment }\end{array}$} & \multicolumn{2}{|c|}{$\begin{array}{c}\text { Drogue deployment to } \\
\text { touchdown }\end{array}$} \\
\hline & $\begin{array}{c}\operatorname{Max} \\
(\mathbf{s})\end{array}$ & $\begin{array}{c}\text { Mean } \\
\text { (s) }\end{array}$ & $\begin{array}{c}\operatorname{Max} \\
(\mathrm{s})\end{array}$ & $\begin{array}{c}\text { Mean } \\
\text { (s) }\end{array}$ & $\begin{array}{c}\text { Max } \\
(\mathrm{s})\end{array}$ & $\begin{array}{c}\text { Mean } \\
\text { (s) }\end{array}$ & $\begin{array}{c}\operatorname{Max} \\
(\mathbf{s})\end{array}$ & $\begin{array}{c}\text { Mean } \\
\text { (s) }\end{array}$ \\
\hline$+\mathbf{R}$ & 1.63 & 0.85 & 42.93 & 7.73 & 3.83 & 0.55 & 130.83 & 49.30 \\
\hline$-\mathbf{R}$ & 1.63 & 0.88 & 53.10 & 14.40 & 5.50 & 1.20 & 125.35 & 39.37 \\
\hline$+\mathbf{P}$ & 2.15 & 1.72 & 4.80 & 1.70 & 16.23 & 10.92 & 0.05 & 0.00 \\
\hline$-\mathbf{P}$ & 2.43 & 1.85 & 5.80 & 2.41 & 17.10 & 11.76 & 0.05 & 0.00 \\
\hline$+\mathbf{Y}$ & 0.83 & 0.44 & 2.48 & 0.72 & 15.63 & 9.88 & 0.05 & 0.00 \\
\hline$-\mathbf{Y}$ & 0.93 & 0.49 & 1.83 & 0.39 & 16.73 & 9.95 & 0.05 & 0.00 \\
\hline
\end{tabular}

Table 4 shows the propellant usage results for the various modification options for the ballistic and constantbank mode entry trajectories. All of the options that are presented below have no rate damping while the touchdown control is in use. The ballistic mode was selected for further study over the loads-managed guidance mode because it is the simplest and most reliable entry abort mode to use in a contingency situation. The constant-bank mode is also being considered because it is a simple flight mode and because it tends to demonstrate a lower total 2- $\sigma$ propellant consumption. It should be noted that the constant-bank mode is not a baselined entry down mode; however, constant-bank flight can be achieved fairly easily by (1) flying manual bank control, (2) using loads-managed guidance with suppressed bank reversal, or (3) using the entry constant-bank mode created to follow an ascent abort.

Table 4. End-to-End CM Propellant Usage for Various Degraded Entry Abort Modes

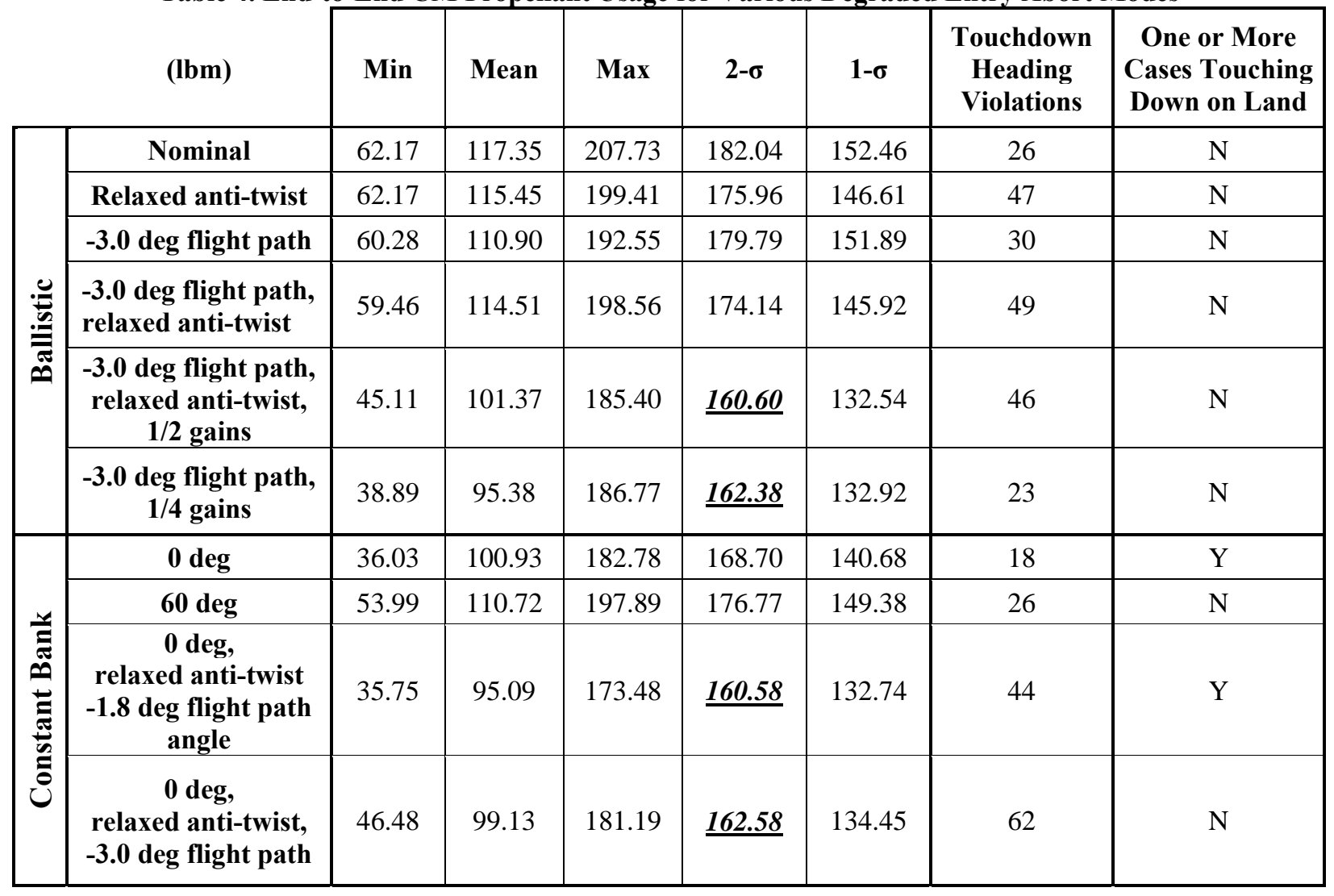


In Table 4, four possible solutions are evident that achieve a 2- $\sigma$ fuel usage of less than 165 lbm (these are shown in the table in bold and italics). However, the two constant-bank cases that are 2- $\sigma$ fuel compliant are deficient in other areas. The case with the nominal (-1.8 deg) flight-path trajectory had a large number of cases that touched down on land; the case with the steep flight-path trajectory had touchdown heading violations in excess of those permitted for 2- $\sigma$ compliance. Both of the ballistic cases were successful in that the touchdown heading accuracy was 2- $\sigma$ compliant and that all cases landed in the water. Furthermore, no cases tumbled prior to deployment of the drogue chutes despite the reduction in pitch and yaw rate damping gains.

As the touchdown control is degraded, the touchdown heading violations increase in number. Figures 6 and 7 show the touchdown plots for the nominal ballistic mode and for the ballistic mode with no drogue damping, respectively. The heading violations increased from 6 for the nominal ballistic mode (Fig. 6) to 26 for the ballistic with no drogue damping (Fig. 7).

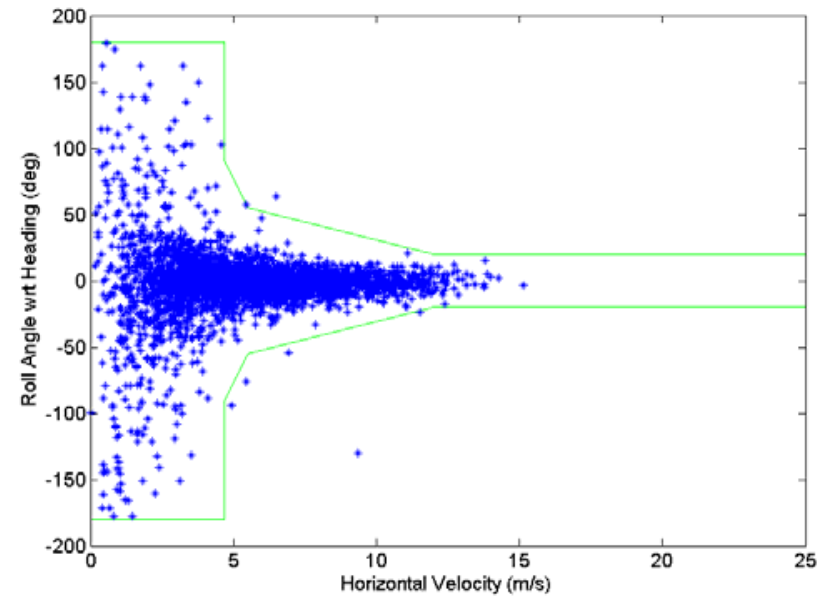

Figure 6. Nominal ballistic touchdown heading.

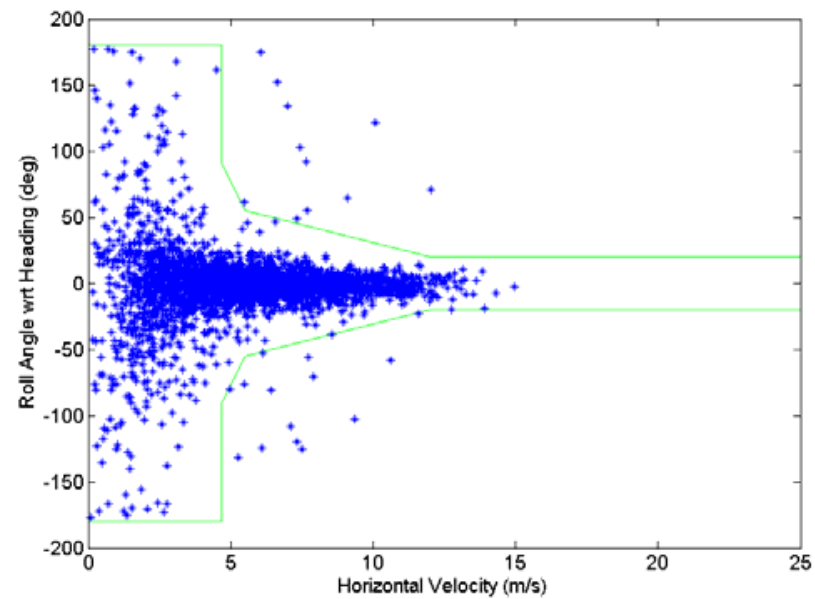

Figure 7. Ballistic touchdown heading without drogue damping.

Figures 8 and 9 show the touchdown orientation plots for the nominal constant-bank mode and the constant-bank mode with no drogue damping, respectively. The number of heading violations increased from only 2 for the nominal constant-bank plot (Fig. 8) to 18 for the constant-bank plot with no drogue damping (Fig. 9).

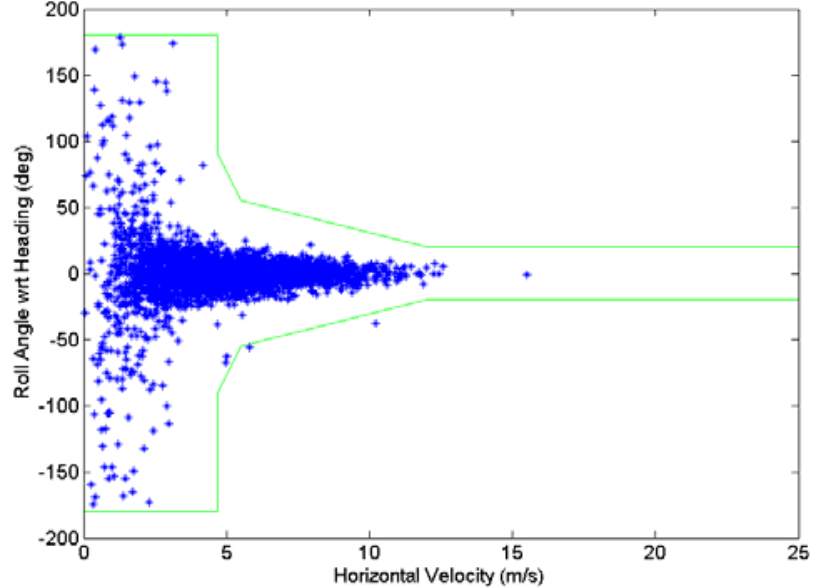

Figure 8. Nominal constant-bank touchdown heading.

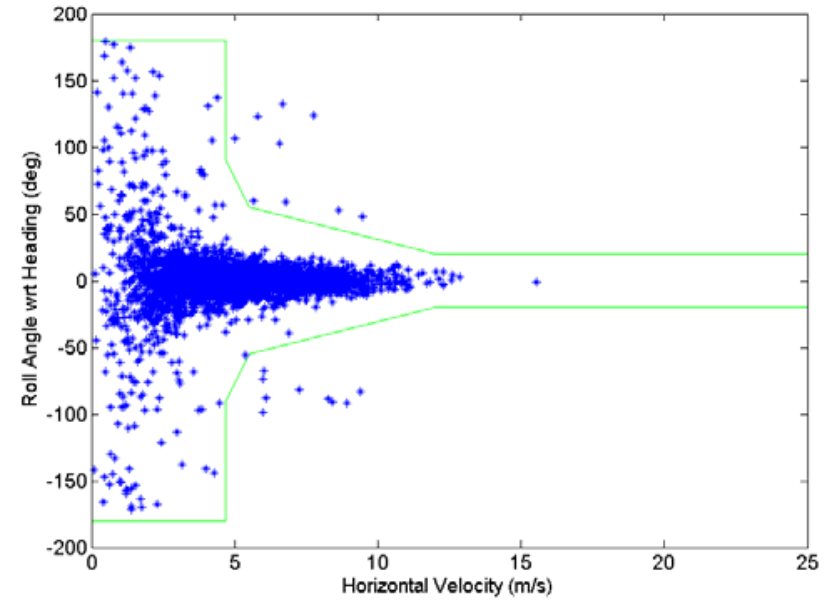

Figure 9. Constant-bank touchdown heading without drogue damping. 
The constant-bank mode with a 0 deg bank command flies lift up. As a result, a significant portion of the cases fly a long trajectory with a touchdown occuring on land. In order to avoid a touchdown on land, a steeper trajectory with flight path angle of -3.0 deg can be used. Figure 10 shows the constant-bank landing point for a 0 deg bank command with a nominal flight path angle of $-1.4 \mathrm{deg}$. Figure 11 shows a constant-bank landing plot with a $60 \mathrm{deg}$ bank command for a flight path angle of $-1.4 \mathrm{deg}$. Figure 12 shows a simulation with a 0 deg bank command but with the steeper flight-path angle of -3.0 deg.

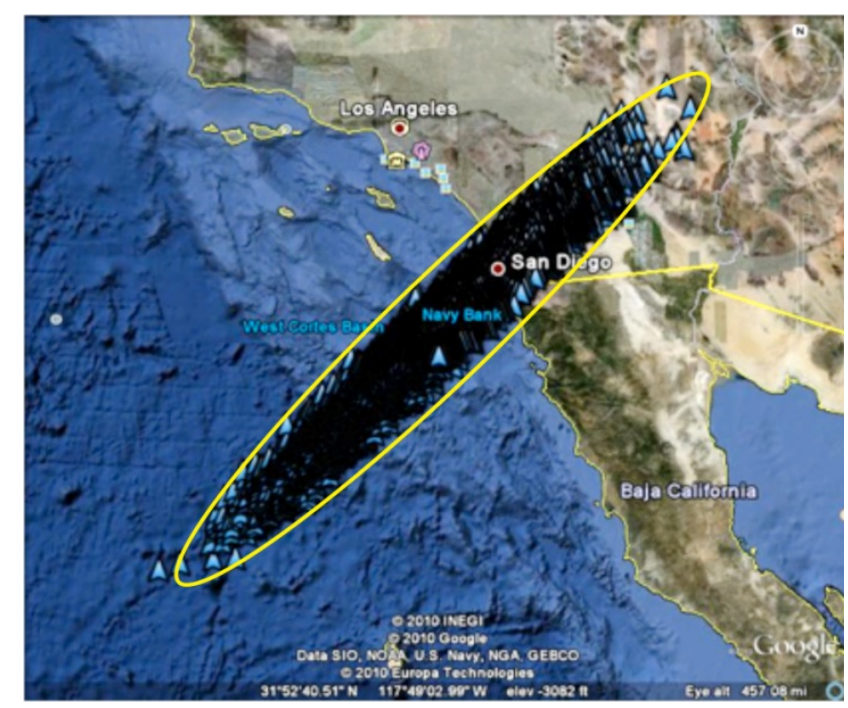

Figure 10. Constant-bank landing points using 0 deg bank command.

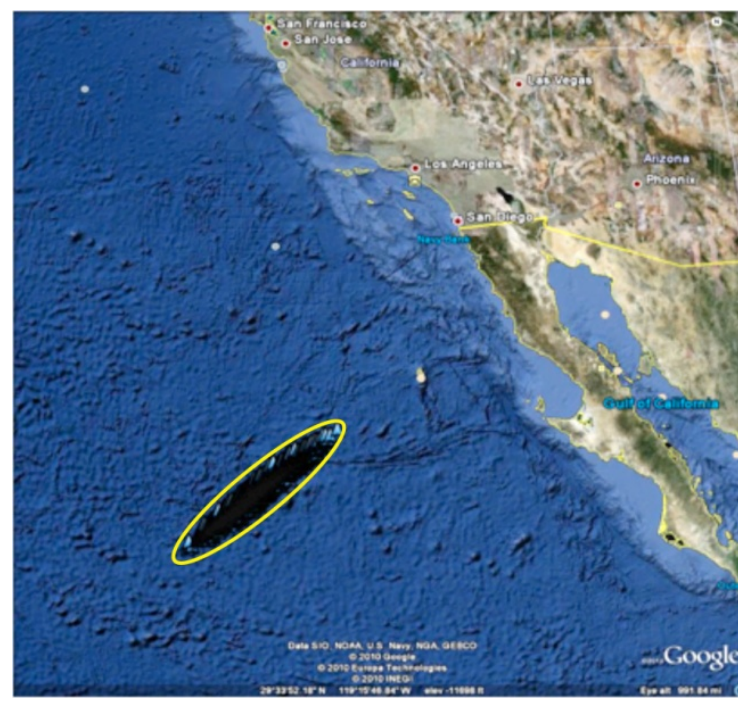

Figure 11. Constant-bank landing points using 60 deg bank command.

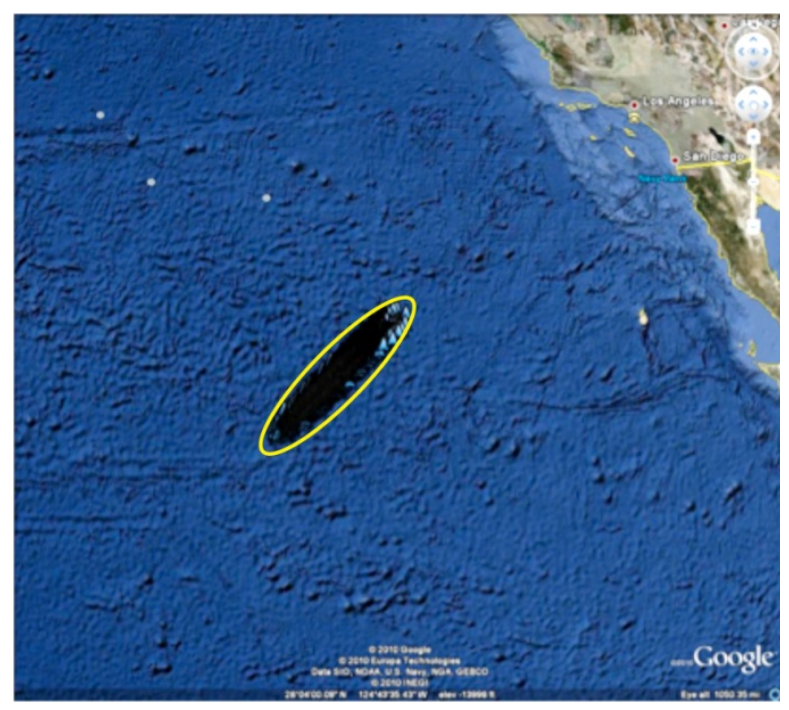

Figure 12. Constant-bank landing points using 0 deg bank command and steep flight path $(-3.0 \mathrm{deg})$.

Care must be taken in designing trajectories that use a constant-bank entry. A lift-up, 0 deg bank-lofted trajectory can reach land if the initial flight-path angle is not adjusted to provide a steeper trajectory. More analysis may also be needed to ensure that thermal heat loads are not violated. For these reasons, a ballistic abort entry is the pre- 
ferred down mode for reduced propellant usage. Ongoing optimization of the flight control gains and deadbands for the ballistic mode should result in a simple, robust algorithm with good performance and low fuel usage.

\section{Conclusion}

Achieving a safe crew module (CM) entry following departure from the International Space Station is feasible using less than half of the available propellant if we assume that the verification compliance can be relaxed to a 2- $\sigma$ level. Going forward, more research is required to select the best design for guidance, navigation, and control entry operations after a CM propulsion tank isolation fault. One potential solution is to fly a ballistic entry abort mode with no CM raise burn and with degraded touchdown control settings. The flight control gains for the ballistic mode may need refinement to minimize fuel usage with a minimum impact on stability and performance.

\section{Acknowledgments}

The author would like to thank Brian Hoelscher, Jeremy Rea and Timothy Crull, all of NASA Johnson Space Center.

\section{References}

${ }^{1}$ Project Orion team, “GN\&C Design and Data Book,” NASA CEV-T-078005, 2009.

2Orion Mission Analysis, “Orion Vehicle Simulation Data Book,” NASA CEV-MA-10-012, 2010.

${ }^{3}$ Fergason, S., “Updated MR-104 Thrust \& Isp Prediction Algorithm,” NASA CEV_CM Prop-09-088, 2009. 